\title{
The Role of Information Technology in Media Industry
}

\author{
A Waseem Khattak \\ Sarhad University of Science and Information Technology Peshawar Pakistan \\ Muhammad Nasir
}

\begin{abstract}
At the dawn of a new era, vast expansion of human communication is profoundly influencing culture everywhere. Revolutionary technological changes are only part of what is happening, which is unifying humanity and turning it into what is known as a global village. But it is changed in the concept of global room, because recent decades also have witnessed remarkable developments in the technology of communicating.
\end{abstract}

These includes both the rapid evolution of previously existing technologies and the emergence of new telecommunications and technologies, satellites, cable television, fiber optics, video cassettes, compacts disks, computerized image making and other computer and digital technology and much more else. Obliviously this is the age of information technology that information technology brought a revolution in the field of media industry also.

The conventional mass media has been replaced by up to date most complicated and most sophisticated. Along with this technological advancement media industry growing fast and rapid. Information revolution had made the information process speedy and rapid, news and information can be sent in a flash to any corner of the world.

When printing press was not invented that time newspapers were published in hand written shape. Today in this age of information technology the use of computer is the part media industry (Print, Broadcast, Electronic and Advertising Agency, News Agency and Films). Composing, printing, animation, diagrams, audio, video visuals, large data storage and centralized newspapers, magazines publishing is only possible through this advance system. Online newspaper editions are also possible through this rapid technology.

In recent years, the explosion of new media --- particularly the Internet --- has caused new anxieties. Or to put a more McLuhanesque spin on it, the advent of the new digital media has 
brought the conditions of the old technologies into sharper relief, and made us suddenly conscious of our media environment, in the confusion of the digital revolution.

\section{Historical Background}

The Information Society or Information Age is a new phenomenon since 1950 which brings with it new challenges as we seek to integrate an expanding universe of print and multimedia sources into our daily lives. The two terms often are used to describe a cybernetic society in which there is a great dependence on the use of computers and data transmission linkages to generate and transmit information. By contrast, our familiar reference frame of an industrial society relied on machines to augment human physical labor to produce goods and services. Now, through a process of continual change, geographic barriers are being dissolved, businesses are more interconnected, and relationships between workers and workplace are changing more rapidly.

In the twentieth century there has been a radical transformation in the role of information in society as well as in the technology used in its production and dissemination. At the turn of the last century, printed information reigned supreme in Europe and North American communities. This, of course, is no longer the case. New electronic forms of communication have multiplied, reducing the primacy of the print medium, but not yet displacing it. Instead, each new form of communication has supplemented printing and publishing.

The evolving electronic information systems also pose new directions for issues that have been around for some time. Take literacy as an example. It is not longer sufficient to be print literate, i.e. to read and write, and the idea of audio or video visual literacy has in turn been supplanted by stress on computer literacy. Literacy has come to be seen as the ability to use information in various forms that it is presented in and to master the skills and techniques necessary to use the systems involve $d$ in managing information, a.k.a. computers. Most commentators seem to see this new literacy not only as an expansion of traditional literacy but also an expansion that requires the development of new skills and new ways to deal with information. 


\section{History of Computer Technology}

A complete history of computing would include a multitude of diverse devices such as the ancient Chinese abacus, the Jacquard loom (1805) and Charles Babbage's "analytical engine" (1834). It would also include discussion of mechanical, analog and digital computing architectures. As late as the 1960s, mechanical devices, such as the Marchant calculator, still found widespread application in science and engineering. During the early days of electronic computing devices, there was much discussion about the relative merits of analog vs. digital computers. In fact, as late as the 1960s, analog computers were routinely used to solve systems of finite difference equations arising in oil reservoir modeling. In the end, digital computing devices proved to have the power, economics and scalability necessary to deal with large scale computations. Digital computers now dominate the computing world in all areas ranging from the hand calculator to the supercomputer and are pervasive throughout society. Therefore, this brief sketch of the development of scientific computing is limited to the area of digital, electronic computers.

The evolution of digital computing is often divided into generations. Each generation is characterized by dramatic improvements over the previous generation in the technology used to build computers, the internal organization of computer systems, and programming languages. Although not usually associated with computer generations, there has been a steady improvement in algorithms, including algorithms used in computational science. The following history has been organized using these widely recognized generations as mileposts.

\section{Internet Journalism}

\section{News on Internet}

For years, publishers of newspapers, magazine and other print products have been fascinated with the idea of delivering information electronically. In contrast to conventional printing on paper, delivery by computer and other means seemed to offer several benefits both the producer and consumer.

Second, information be disseminated to readers much more quickly than it could in printed publication. The bulk of information in a daily newspaper is at least 12 hour old; articles in a monthly magazine are often written three or for months before they are published. 
During the next decade, publications turned to several other means of delivering information electronically. Some hooked up with online services such as CompuServe and America Online. Other experimented with fax editions and computer bulletin boards. A range of media companies tried their hands at producing CD-ROMs, delivering information by satellite and e-mail, N11 services (using three-digit phone number like 911) and a number of other methods.

\section{Evolution of Internet Journalism}

1995: the Year the web Exploded in 1995, electronic delivery came to age. At of 1993, 20 newspapers worldwide - and a few magazines an newsletters - were published electronically, mostly on online services such as prodigy and CompuServe. During 1994, the number of online newspaper reached to thousands.

At this relationship between the journalist and the technical means of gathering and reporting information emerges, we see a new breed of communicator, the techno journalist. In reporting, working and thinking, the journalist of the future will be different from those of today. The journalist of the future will have to balance the humanistic sensitivity that produces best journalism with newfound technological tools, journalists must not settle for becoming mere scientists' apprentices; they will have look at the impact of technology on values.

In the future, the mass-media journalist may be the exception rather than the rule. The journalist will have to sain a deeper, more diverse understanding of communication, largely because of the way information will be stored-in databases.

\section{Web-offset}

Photo setting was made possible by the computer but it owed its utilization to the web-offset printing process. The continuance of hot metal typesetting and page make - uphad been unchallenged because it suited the plate making process used in letterpress printing. The plates could be cast conveniently in metal from the moulds taken from the made up pages .the plate makers shared the same hot metal and foundry facilities as the line casters which were located usually on the same floor moreover metal plates I heavy relief had always been 
regarded on the only way type could be transferred successfully to newsprint by means of the high speed rotary presses used to print modern newspapers.

Thus newspapers that the new plates were considerably lighter than the $18 \mathrm{~kg}$ conventional stereotype metal plate. A disadvantage was that, while the durability and cheap running of the rotary presses had been married to the cost-saving of cold type technology, plate-making time had been considerably increased and edition schedules upset by the extra procedures needed to convert pasted-up pages into metal printing plates. This was alleviated when the development of tougher polymer in the early 1980s, enabled traditional rotary presses to be used for direct printing from polymer plates derived from pasted-up pages.

\section{De-centralized Printing}

Page facsimile transmission is a technique whereby made-up pages can be photographed and transmitted from the main production centre to satellite printing plants within the circulation area so that the printing operation can be carried out simultaneously at several centers.

The page photographs digitized by means of scanners so that the data is compatible for sending by microwave, for short distances, or by broadband telephone lines or earth satellite for longer distances. The signal is encoded by a special receiver at the other plant and is made into a page transparency. This is fed into a plate-maker which produces a polymer printing plate identical to the one being used in the main centre. The average transmission time is about three and a half minutes.

This makes it an attractive proposition in countries, especially in the Third Word, in which the use of satellite printing centers can be the answer to communication and distribution problems.

In Britain, to help in efficient distribution, a number of provincial and national newspapers, including The Guardian, Daily Mirror, Daily Star, the Sun and News of the World, are using page facsimile transmission for all or part of their production outside London, while The Financial Times and the Wall Street Journal circulate internationally on the same day by this means. Even Pravda uses the technique to reach for confines of the USSR. 
The used of computerized systems has meant the down of the electronic newsroom, with news editors checking reporters ' files on the screen, sending back stories where coverage is not sufficient or has failed in some way, and routing stories to the copy-taster and the subeditors as they become ready.

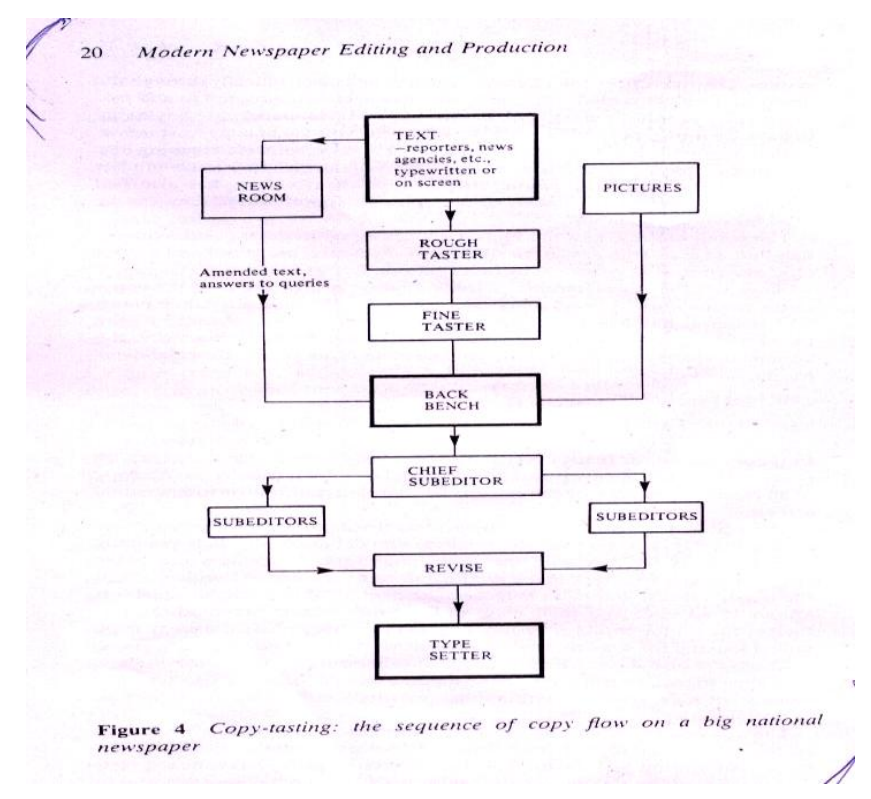

\section{Tasting Methods}

The effect on news copy-tasting of electronic copy inputs is more apparent then real. Whether on screen or on hard copy the basic routine of the job is the same. Important stories are drawn to the attention of the night editor or chief subeditor; the clearly dead ones are spiked, the doubtful but possible once put into a separate pile to be turned over in moments of need, the likely topes of pages put aside for use as page planning proceeds.

Some national papers refine the tasting process by filtering copy through a rough and a fine copy-taster, or through separate home and foreign tasters. The aim is not only a fail-safe reading operation but a continuously creative assessment of the copy flow to pin-point things that might otherwise be missed. 


\section{Electronic Copy-tasting}

Electronic copy-tasting, in which the taster reads from the screen, is necessary one direct input of copy is adopted - when reporters and correspondents type their stories directly on to a VDU instead of a typewriter, or when their telephoned copy is likewise entered into the computer by the telephone copy-takers. Once such copy has been cleared by the newsroom it can be recalled from its 'queue' in the computer for tasting and, after that, for page planning and editing.

Electronic copy-tasting is made easier not only by the taster being able to call up stories at a stroke, but by being able to call up the complete 'directory' of stories held in a given queue (i.e. newsroom, agency, sport, etc.) which gives the source, name and catch-line and the first few lines of each story, and also its length.

The different stages which computerized technology has reached in the various production centers has resulted in news agencies - the principal suppliers of news copy in any country having to maintain a variety of services to satisfy all their subscribers.

\section{Electronic Editing}

With direct input of copy into the computer the subeditor the advantage of electronic aids in editing. As with copy tasting, the ease of operation is greatest where everything comes through the computer, rather than with come subbing still having to be done on hard copy. Subeditors who have become familiar with screen editing do not usually like to go back to subbing hard copy.

Stories can be checked for length by relating the word count and number of line given in the screen 'header' to the space allocated on the page layout. Fact and word pruning are then carried out as with hard copy subediting. The difference is that the use of the cursor, or electronic pen, on screen enables deletions and alterations to be make faster than by ball pen, while at the same time resulting in instantly clean copy without the scribbles, scorings and connecting lines that characterize hard copy subbing. After each change or alteration the text automatically rearranges itself on the screen. 
Split screen, on which two stories are displayed side by side, can be used when working on copy from another source. Deleted material may be also left in the computer in 'note' form from which it can be reactivated and brought back into the text, if needed, by a simple command stroke. With electronic editing, copy is capable of almost endless reworking and revising as it is with any word processor-while at the same time finishing up clean and ready for typesetting. Moreover, after a story has been checked and cut to fit it can be scrolled back for re-reading on the screen and any late alterations made with greater ease than would be the case with already heavily subbed hard copy.

Modern systems have facility for delivering print-out proofs after the $\mathrm{H}$ \& $\mathrm{J}$ stage showing the story as it will look when typeset. These are useful if the story needs to be taken away-for telephone checking, stay. In fact, many newspaper offices make little use of the facility once direct input has transferred the whole editing operation into the computer. Nor is the print-out proof needed to increase the distribution of a story within the editorial department since it is now possible to generate 'carbon' copies of a story within the system. This means that it can not only be read by one person versions for use in different papers fed from the syste

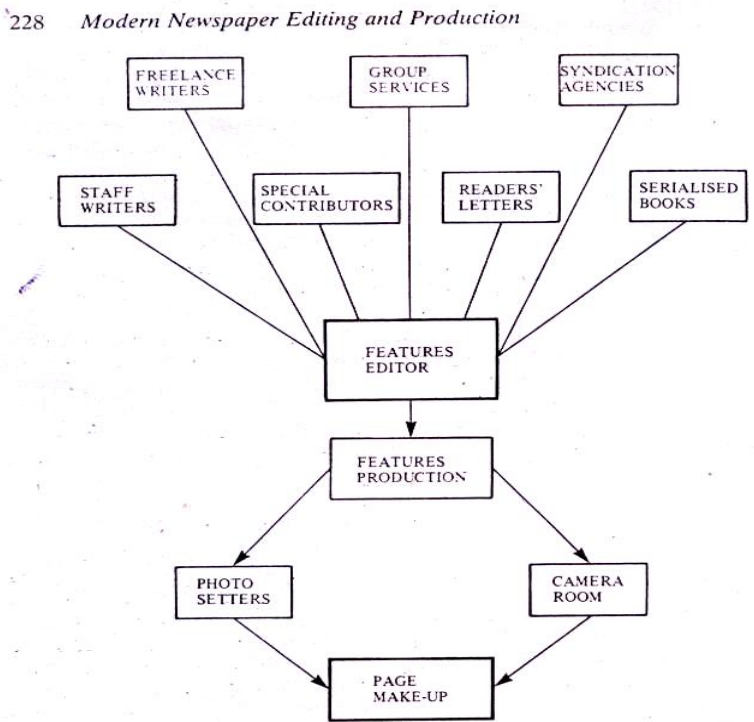

Figure 39 The flow of work through the features department of a big modern newspaper

PRINTING PLATE

Figure 33 An example of work-flow in a modern computerized composing room 


\section{Electronic Mail}

Electronic mail (E-mail) is a system for sending messages or files to the accounts of other computer users. The sender and recipient may be on the same or a different computer. Electronic mail works very much like regular postal mail .Every user on the net work has a private mailbox. Once received, your mail is kept for you until you decide to discard it. Like regular postal mail, you must know a user's address to send messages. If the mail system cannot deliver your message, it will make every attempt to return it to you, but is possible for misaddressed messages to get lost somewhere along the way.

\section{Newspaper and Television Newsroom}

- Newsroom computers chapter the keystrokes of reporters and editors, eliminating the need for keyboarding that took place in the "good old days" when reporters wrote on manual typewriters (see figure 1.1). Without computers, newspapers would have to hire people to fill all those positions eliminated in the computer revolution.

- Computers make it possible for reporters to cover stories that were simply impossible to write in simpler times. It would take several reporters several lifetimes to do the data analysis to done on computers.

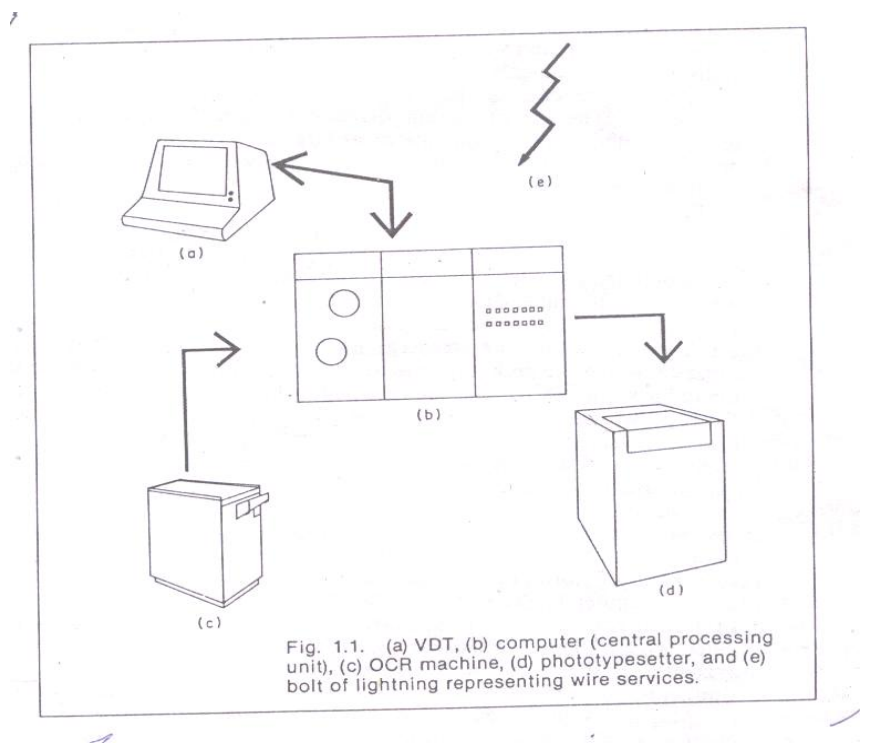


All electronic editing systems are built around computers. Newspapers quite commonly use a computer to handle ad billings, subscription lists and payrolls as well as news stories. Larger papers are more likely to have separate computer for the news operation. You can think of the computer as a big file. Before you can get something out, something has to go in. input is handled in a variety of ways. Here are the four main ways:

1. Direct keyboarding-you type on a VDT hooked up to the computer.

2. Scanner copy-reporters type scanner copy and run it through the optical character recognition (OCR) machine. This machine reads copy electronically and puts it directly into the computer.

3. Computer-to-computer hookups-the wire services send material to your computer at great speed; you hear nothing, but you get notes on what is in the system.

4. Paper tape-human operators called tape punchers read your typewritten copy and from it make a perforated tape that can be used to set type directly or to feed a story into the computer. Because it requires extra work, including a second keyboarding of the story, this system is being sup planted by other methods.

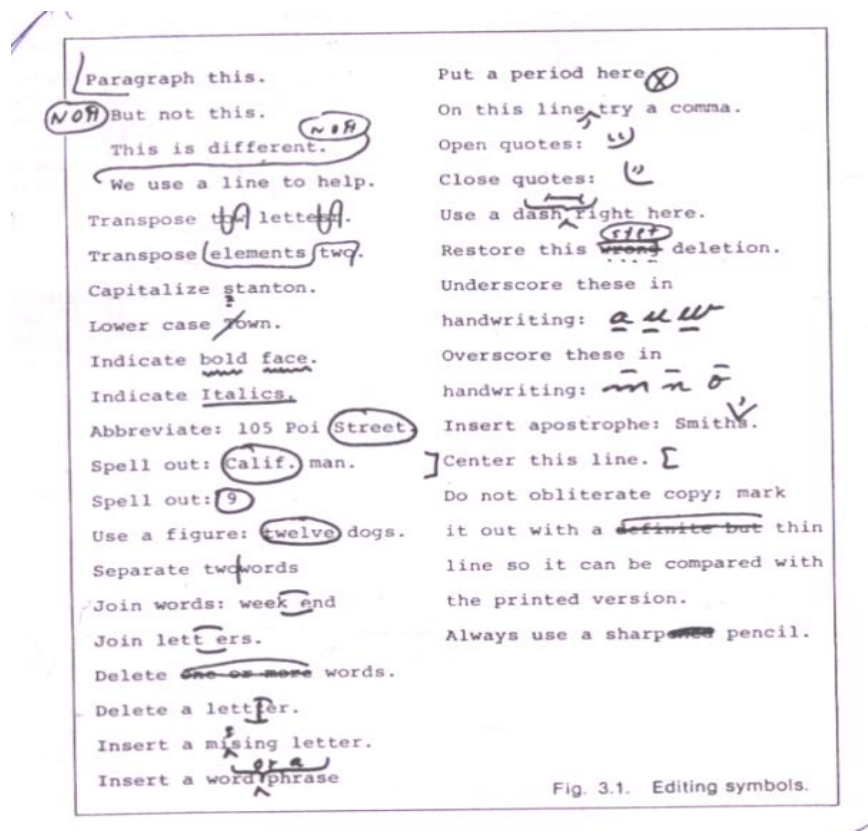

This is the old method of subbing in media industry now a days subbing is done on computer. 


\section{Newspaper Layout}

The electronics people have flushed us out of this final fortress of pencil-and-paper editing. The rout is not complete, but old-style layout work is in its last decade. Pagination, the electronic are term for page layout on a video display terminal, has gone beyond the dreaming stage and crept into newsrooms. The equipment is expensive, it is imperfect and it is best suited to tabloid-size newspapers, but publications are buying it.

Pagination, when used with other electronic editing and printing equipment, offers a number of advantages. You can arrange a page as you want it-you see body type, headlines, cut lines, boxes and blanks for photographs. When you press the go button, the page zips through the computer and comes out full size, ready to be photographed in the plate-making process. The day is coming, shortly, when your page-size VDT will be connected directly to the press, and any change on the VDT image will result in an immediate change on the printed page.

\section{Newspapers Adapt to Cope with the New Media}

For decades the entertainment-information business has been dominated by newspapers, television and radio in an environment of relative media stability. Now the host of electronically based, untested, computer-oriented information systems we call the new media threatens to change the basic structure of the communications industry. And that change is already taking place. Whether from fear of competition or hunger for profits, established media are increasingly hedging their communication bets and involving themselves one or more new media enterprises.

\section{Reactions to Changing Nature of Journalism}

New media are accompanied by many new and challenging ideas about how to gather, store, process and deliver information, and, at the same time that they are branching out into the new fields, newspapers are using these newly learned concepts to restructure internal operations as well. Indeed, corporate impact on communications businesses. Journalism, after all, is a tradition-steeped business.

Journalists tend to see their calling in strict terms of truth and falsehood, unchanged by war or riot, by invention or economics. But journalism, as a profession and as a set of standards, has never been independent of the tools used to communicate a given message. The changes 
required by the new media and the evolving communications environment are no exception, and it is evident that they will come. Whether their impact is felt mostly in the $1980_{\mathrm{s}}$ is irrelevant because they must be anticipated and confronted now.

\section{Group Collaboration}

As the networks mature, it is increasingly obvious that they are not merely a vehicle for conveying endless amounts of information to the desktop, but can provide an effective platform for working with colleagues, irrespective of location. The $\mathrm{u}$ se of the www for collaboration is currently the focus of much interest and development and many interesting new tools are appearing which make online collaborative projects a realistic, if not attractive, option for distributed workgroups. You can use the internet for sions, working on documents, and a range of other tasks.

\section{Holding Meetings}

Meetings with other network users using facilities such as videoconferencing are no longer a futuristic dream, especially for users on high-speed connection in the academic and research communities. And for quality communication, there is nothing quite like interactive dialogue with a person you can see and hear, even considering the benefits and convenience of tools like email. Meetings using network videoconferencing and audio conferencing enable network users to have the immediacy of face-to-face meeting. This includes the experience of real personalities, with the potential benefits of seeing spontaneous reactions sorting out problems on the spot, getting instant feedback on ideas, not to mention saving on travel costs.

\section{Video Conferencing}

Videoconferencing and audio conferencing are powerful facilities when they work well, but not all network users have a benefit of the high-speed connection required. They may instead need to look at systems for the interactive exchange of plain-text messages such as chat. Chat is also commonly included in collaboration software. It may not be as glamorous as phone and videoconferencing tools, but it does have the advantage of people on low-speed connection. 


\section{Discussion Forums}

Collaborating with others usually means ongoing discussions which add and flow depending on what's happening in the workgroup. Internet discussion forums provide an ideal vehicle for this type of activity. Messages can be posted to the discussion is usually available, enabling the group to refer back to previous messages. The software to access such forums is generally easily accessed, installed, and used.

The net excels in providing such facilities for group discussion. Mailing lists and Usenet News have a well established role. There are many web conferencing systems to choose from too. With these, a web browser is used to read text messages in a forum and to add messages to the forum. Conferencing systems are organized by subject with individual conferences devoted to a particular subject. The discussion might then be further divided by discussions on particular topics, referred to as threads.

\section{Exchange Files}

The networking provides a superb transport medium for sending files to other people. They offer fast and efficient transmission over any distance, a choice of system catering for different circumstances, and a range of application software to facilitate the transmission or distribution of files. Application software may also automatically take care or any associated processing, for instance converting binary files to text format for E-mail transmission and converting then back to binary, when sending files select a method and a format which suits your recipient as well as yourself. The main option for exchanging files is discussed below.

\section{Text Messaging}

Text messaging, also know as short messaging service (SMS) is all the range in Europe and parts of Asia. Teens and adults walk around looking and typing on their phones instead of talking of them. In May of this year, 19 billion short messages were sent, according to the Global system for Mobile communication (GSM) Association. People in the U.S. may be using one way SMS without Knowing it-text updates delivered to phones (sports scores, news headlines, etc.) are sent in part via SMS. 


\section{Computer Graphics}

Computer has become a powerful tool for the rapid and economical production of pictures. There is virtually no area in which graphical displays cannot be sued to some advantage, and so it is not surprising to find the use of computer graphics so widespread. Although early applications in engineering and science had to rely on expensive and cumbersome equipment, advances in computer technology have made interactive computer graphics a practical tool. Today, we find computer graphics used routinely in such diverse areas as business, industry, government, art, entertainment, advertising, education, research, training, and medicine.

\section{Animation}

\section{Computer-Based Animation}

To animate something is, literally, to bring it to life. An animation covers all change that have a visual effect.

A computer- based animation is an animation performed by a computer using graphical tools to provide visual effects. We concentrate in this section on computer-based animation because this kind of animation will become part of multimedia systems.

\section{Creating Animation}

Creating a series of images shown in below Figure Each image supersedes the previous images with a minute change that, over time and rapid play back presents on illusion of motion by the content of the segment.
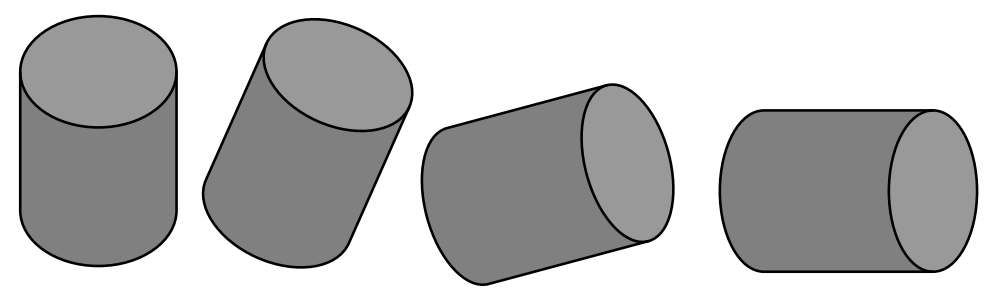

Animation is a serial of images viewed sequentially. Each image depicts a position and when viewed succession illustration motion.

Animation software tools enable developers to rapidly build a succession of images by group's objects and managing backgrounds. The final product is output a file for later 
playback. In some cases, the output file is compressed using the same algorithms as used for analog video capture.

\section{Conclusion}

In the information era, computer will be integrated into every society and will do much to improve the quality of life information technology opened new doors for media industry No doubt this is the age of information technology, media industry has also made tremendous progress due to this new technology. Due to this new advancement media is fragmented, media manipulated and information is overloaded. Through this new technology media is now growing fast, realizing the importance of information and communication technology.

The introduction of IT in the country has led to varying degree of improvement in media industry. Here is no doubt that IT was a tremendous Role in media industry but there is a big gap among both organizations. Due to this advance technology advertising, production media printing, broadcasting, telecasting and in web edition of news papers had a great progress. We can conclude that IT has a great role in print, broadcast, electronic and advertising media. Without IT media in this age of information cannot survived. 


\section{References}

- (2000) Pakistan Must Have An It Vision, Pakistan

-. "The Return of the Luddites." Wired (June 1995): 165.

-. Ed. Hyper/Text/Theory. Baltimore: Johns Hopkins University Press, 1992.

-. The Medium is the Massage. New York: Bantam Books, 1967.

-. The World Turned Upside Down. New York: Penguin Boks, 1975.

----------. Undertanding Media : The Extensions of Man. Cambridge: The MIT Press, 1995.

-----------2000) Cyber.Net Making the Difference, Pakistan.

Bansal.K.S. (2003): “Multimedia System” New Delhi: APH publishing corporation.

Corey, Sandler (1986): “How To Telecommunicate” USA: Henry Holt and Company.

Federal Bureau Of Statistics (2002) Census Of Software Industry And Related

Ghauri, S (2003) Information Technology status in Pakistan, Pakistan.

Giamburuno, Mark (2002): “3D Graphics And Animation” India: Pearson education Singapore.

Gibson.L, Martin (1986): “Editing In The Electronic Era” New Delhi: Prentic-Hall of India private limited.

Gupta, om and Jasra. S,Ajay.(2002): “Information Technology an Journalism" New Delhi: Kanishka publisher, Distributers.

Gupta, om and Jasra. S,Ajay.(2002): “Information Technology an Journalism” New Delhi: Kanishka publisher, Distributers.

Hearm, Donald and baker, Pauline. M: (1986) “Computer Graphics” New Delhi: Hall of India Private Limited.

Hill, Christopher. "Political Discourse in Seventeenth Century England." Politics and People in Revolutionary England, edited by Colin James. Oxford: Basil Blackwell Ltd., 1986.

Hodgson .W. F. (1997): “Modern Newspaper Editing and Production” London: Hineman professional publishing Ltd.

Hodgson. W.F (1984, 1989): “Modern Newspaper Practice” UK: Heinemann professional Publishing LTD.

Imam, Z (2000). Status of Information Technology in Pakistan, Pakistan.

Johnson, Steven. "Downsizing the Revoution." FEED (archived at: http://www.feedmag.com).

Joycelyne, Andrew. "Revolution in the Revolution." Wired (January 1995): 116. 
Katz, John. "The Age of Paine." Wired (May 1995): 154.

Kernan, Alvin. Printing Technology, Letters and Samuel Johnson. Princeton: Princeton University Press, 1987.

Kline, Davis and Daniel Burstein. "Is Government Obsolete?" Wired (January 1996): 88.

Kuhn, Thomas. The Structure of Scientific Revolution. Chicago: The University of Chicago Press, 1962.

Landow, George P. Hypertext: The Convergence of Contemporary Critical Theory and Technology. Baltimore: Johns Hopkins University Press, 1992.

Lapham, Lewis. "Introduction." Understanding Media: The Extensions of Man, written by Marshall McLuhan. Cambridge: The MIT Press, 1995.

Lsaacs, Margarate. (1998): "Internet Users Guide to network resource tools" England: Dorest press.

McLuhan, Marshall. The Gutenberg Galaxy: The Making of Typographic Man. Toronto: University of Toronto Press, 1962.

Milton, John. Archeopagitica. Excerpted in The Norton Anthology: English Literature, edited by M. H. Abrams. New York: W. W. Norton \& Company, 1993.

Patten, A, David (1986): “Newspapers And New Media” USA: Knowledge industry publication.

Richardson, R.C. The Debate on the English Revolution. New York: St. Martin's Press, 1977. Ruggirello, Frank. (1995): “Every Student's Guide to the internet” Newyork: Mc Graw-Hill. Ruggirello, Frank. (1995): “Every Student's Guide to the internet” Newyork: Mc Graw-Hill. S.Brain, Brooks (1997): “Journalism In The Information Age” USA: Allyn and Bacon. Satellite Magzine, February 2006.

Services of Pakistan, reproduction and printing unit, FBS, Karachi, Pakistan.

Shabbir H.K (2000) The Status Of Information Technology In Pakistan, Pakistan

Sharpe, Kevin. "Crown and Parliament." The Making of Britain: The Age of Expansion, edited by Lesley Sharpe. New York: St. Martin's Press, 1986.

Siebert, Frederick. Freedom of the Press in England 1476-1776. Urbana: University of Illinois Press, 1952.

Snyder, Ross. "Architects of Contemporary Man's Consciousness." Inter/Media, edited by Gary Gumpert and Robert Cathcart. New York: Oxford University Press, 1982.

Sontag, Susan. "The Imprisoning of Reality." Inter/Media, edited by Gary Gumpert and Robert Cathcart. New York: Oxford University Press, 1982. 

Volume: 2 - Issue: 3 - July - 2012

Xian, Zhigang. Plastock,A, Roy (2001): “ Computer Graphics” New York : Mc Graw-Hill. 